\title{
EDUCAÇÃO AMBIENTAL: POSSIBILIDADES E DESAFIOS NO PROCESSO ENSINO- APRENDIZAGEM DA GEOGRAFIA ESCOLAR
}

Isonel Sandino Meneguzzo ${ }^{1}$

Paula Mariele Meneguzzo ${ }^{2}$

RESUMO: O objetivo deste texto é o de identificar as possibilidades e os desafios de se trabalhar a educação ambiental no âmbito da Geografia escolar utilizando-se da abordagem crítica. Diversos procedimentos didáticos podem ser realizados com os educandos para se abordar aspectos envolvendo a educação ambiental. Apesar dos problemas de organização e estrutura que atingem as instituições de ensino, a educação ambiental na Geografia pode ser aplicada para solucionar e minimizar problemas socioambientais. Pautado numa perspectiva interdisciplinar e levando em consideração a boa aplicabilidade dos conhecimentos geográficos e da abordagem teóricometodológica fundamentada na criticidade, tal postura dos docentes permite contribuir para que os estudantes possuam uma formação abrangente e uma visão crítica em relação à questão socioambiental.

Palavras-chave: Ensino de Geografia; Educação Ambiental. Geografia escolar.

${ }^{1}$ Professor Assistente A, Departamento de Geociências, Universidade Estadual de Ponta Grossa (PR). E-mail: imeneguzzo@hotmail.com.

2 Docente da Rede Estadual de Ensino do Paraná. Geógrafa e Mestre em Gestão do Território pela Universidade Estadual de Ponta Grossa (PR). E-mail: paulameneguzzo@hotmail.com.

Revbea, Rio Grande, V. 8, № 2:10-19, 2013. 


\section{INTRODUÇÃO}

Nos últimos anos, a educação ambiental (EA) vem recebendo atenção especial dos governantes nas diferentes esferas (federal, estadual e municipal), de organizações não-governamentais, empresários, bem como da mídia em geral. Isso se deve ao fato da profunda crise civilizacional que atinge a humanidade (LEFF, 2008, p.15) e à emergência de possíveis soluções em relação aos problemas socioambientais.

Apesar dos esforços, a EA ainda não teve sua consolidação em termos de efetividade na prática pedagógica e até mesmo enquanto política pública no Brasil, nos diferentes níveis de ensino e, principalmente, nas disciplinas escolares que não estão diretamente ligadas a ela. Apesar do conceito de EA ter sido citado pela primeira vez na Grã-Bretanha, no ano de 1965 (DIAS, 1998) um longo caminho envolvendo diversas abordagens teórico-metodológicas e concepções diferenciadas sobre o que é a EA, vêm sendo trabalhadas, tanto em nível mundial, quanto nacional.

Diante disso, vale destacar que o quadro econômico, político, social e educacional do Brasil é bastante complexo e contraditório (LIBÂNEO, OLIVEIRA; TOSCHI, 2007, p.114) e a questão ambiental não foge a esse contexto. Portanto, a Geografia é de suma importância para os educandos, pois pode possibilitar a compreensão da inter-relação existente entre processos naturais e sociais, do padrão de produção e consumo adotados e atualmente vigentes nos países que adotam o sistema capitalista. Cabe também a esta disciplina contribuir para a tomada de consciência ${ }^{3}$ dos estudantes perante seu papel na sociedade em que estão inseridos.

No atual momento histórico, urge a necessidade de incorporação de valores e atitudes aos conhecimentos sobre processos ambientais para que exista a definição de uma relação de equilíbrio dos indivíduos com o ambiente em que vivem (TOZZONI-REIS, 2008, p.43). A Geografia entendida enquanto uma ciência social que se apropria de conhecimentos provenientes de outros campos do conhecimento pode contribuir nessa direção, apontando os problemas e soluções com vistas a sociedade alcançar patamares aceitáveis em relação à sustentabilidade ambiental.

Partiu-se da problemática de que um número significativo de docentes da disciplina de Geografia (e instituições escolares) não contempla de forma satisfatória o item "Educação Ambiental" na prática pedagógica devido às dificuldades no que concerne à organização no dia a dia do ambiente escolar e a falta de materiais pedagógicos, apesar dos esforços realizados nos últimos anos para se enriquecer as bibliotecas das instituições de ensino em geral.

3 Destaca-se que o termo conscientização é adotado na mesma perspectiva de Freire (1987), onde este autor diz que deve haver um envolvimento mútuo no processo de aprendizagem por meio do diálogo, reflexão e ação no mundo.

Revbea, Rio Grande, V. 8, N²: 10-19, 2013. 
Perante esse contexto, o principal objetivo deste texto, de caráter teórico-empírico é o de identificar as possibilidades e os desafios de se trabalhar a educação ambiental no processo ensino-aprendizagem da Geografia em instituições de ensino fundamental e médio por meio de uma abordagem crítica, levando em consideração as características básicas envolvendo a disciplina supracitada, o contexto das instituições educacionais e os aspectos históricos e legais vigentes alusivos à EA.

\section{MÉTODO}

O presente trabalho foi concebido por meio de revisão bibliográfica com posterior análise das informações coletadas. As fontes pesquisadas envolveram publicações disponibilizadas em meio impresso (livros de caráter científico) e na Internet (Lei no 9.795/99 que institui a Política Nacional de Educação Ambiental e as Diretrizes Curriculares Estaduais de Geografia do Paraná).

Nesse sentido, analisaram-se as informações levantadas utilizando-se de uma perspectiva crítica, levando em consideração aspectos do contexto educacional e a orientação teórico-metodológica atualmente vigente na Ciência Geográfica, fundamentada na criticidade.

\section{O CONTEXTO EDUCACIONAL ATUAL: ALGUMAS CONSIDERAÇÕES}

Para Soffiati (2005) a educação, em seu sentido mais amplo, enfrenta significativos problemas relacionados à qualidade e não alcançou patamares desejáveis de democratização. Apesar dos esforços realizados nos últimos anos por parte do governo, em suas diferentes esferas (federal, estaduais e municipais) o Brasil ainda almeja elevar os índices que indicam a qualidade no âmbito das escolas públicas.

Atualmente, "A crise da educação não está na educação. A crise da educação é tradução imediata da crise de objetivos e da saturação do modelo capitalista" (Calloni 2005, p.69). Vale ressaltar que interesses econômicos internacionais são os responsáveis pela elaboração e vigência de leis que constituem a base legal da educação no Brasil.

Lampert (2005) aponta para o fato de que nunca se deu tanta importância à educação, ao ensino, ao conhecimento, porém, com exceções, percebe-se a instalação do $\operatorname{caos}^{4}$ nas diversas esferas e níveis de escolaridade.

\footnotetext{
${ }^{4}$ Altos índices relacionados à evasão escolar, criminalidade entre os discentes, índices elevados de reprovação e falta de materiais didático-pedagógicos nas instituições de ensino são exemplos de alguns problemas enfrentados na atualidade.
}

Revbea, Rio Grande, V. 8, № 2:10-19, 2013. 
Aranha (1989) aponta para o fato de que a educação e a escola constituem um espaço possível e importante de luta contra-hegemônica, ainda que, evidentemente apresente limites.

No âmbito da educação brasileira ${ }^{5}$, o arcabouço legal permite de modo mascarado, a formação de cidadãos pouco capazes em refletir sobre sua situação social, econômica, cultural e como é a qualidade do ambiente que os cerca. As médias necessárias para aprovação ${ }^{6}$, os índices de reprovação e a própria qualidade no ensino público são os principais fatores deflagradores desta formação inadequada dos estudantes.

Morin (1997) comenta que a educação acabou ensinando as pessoas a separarem e isolarem os fatos ao invés de interligar o conhecimento produzido nos diferentes campos do saber. Existe uma tendência em separar os objetos de seu contexto, de isolar os fatos separando-os do contexto em que ocorrem.

De acordo com Penna (1999) num mundo onde a necessidade humana de valorizar-se e ser respeitado pelos seus semelhantes manifestam-se, de forma crescente, por meio do consumismo e da compra de bens supérfluos, torna-se difícil desenvolver um pensamento crítico e reflexivo em relação à questão socioambiental nas pessoas pertencentes às elites tanto urbanas quanto rurais. A sociedade, ainda valoriza os bens materiais, a beleza física das pessoas, o modismo em detrimento dos valores culturais, científicos e morais. Talvez mais complexo ainda seja promover a compreensão e apreensão de tais valores em pessoas pertencentes às classes inferiores, pois, "É difícil falarmos de sociedade sustentável em um país onde a miséria e a fome ainda estão presentes" (MANUCCI, 2004, p.25).

Pode-se levantar uma questão bastante pertinente na atual conjuntura: como falar em meio ambiente, educação ambiental, desenvolvimento sustentável e conservação da natureza, num contexto marcado pela existência de problemas básicos que afligem parcela significativa da sociedade? A situação é complexa e adversa para os docentes e para a própria escola que certamente devem atuar (e atuam) como assistencialistas para minimizarem a situação, antes de promoverem a Educação, o ensino da Geografia ou a Educação Ambiental.

\section{A GEOGRAFIA NAS ESCOLAS E A APREENSÃO DA EDUCAÇÃO AMBIENTAL PELA GEOGRAFIA}

\footnotetext{
${ }^{5}$ Cf., por exemplo, a Lei número 9.394/96 que trata das Diretrizes e Bases da Educação Nacional.

6 Não significa aqui dar a entender que a reprovação seja sinônimo de ensino de qualidade. Os alunos ao longo do ano letivo possuem diversas chances de recuperar notas/conceitos abaixo da média, porém o que se vê na prática é a displicência tomando conta deste importante momento do processo ensinoaprendizagem.
} 
No âmbito das escolas e colégios, a disciplina de Geografia caracterizada por estudantes e até mesmo docentes como sendo apenas descritiva e informativa (fundamentada no positivismo e no neopositivismo), num passado não muito distante, passou nos últimos anos a ser vista como uma matéria que possui o caráter de criticidade, a qual possui forte influência da vertente marxista.

A Geografia trabalhada nas escolas foi repensada durante a década de 1980 quando o movimento de renovação do ensino desta disciplina fez esforços na melhoria da qualidade do ensino, promovendo uma revisão dos conteúdos, da abordagem metodológica e de sua relação com outras matérias (PONTUSCHKA; PAGANELLI; CACETE, 2007, p.68). Somente a partir da década de 1990 é que os professores do ensino fundamental e médio começaram a adotar uma postura teórico-metodológica fundamentada na criticidade (PARANÁ, 2008).

Em tese ${ }^{7}$, superada a abordagem da simples descrição de fatos e fenômenos físicos e da mera exposição de números alusivos a áreas continentais e populacionais, por exemplo, a Geografia nos dias atuais é vista como uma disciplina apta a contribuir para a formação de um cidadão crítico e atuante enquanto parte constituinte da sociedade democrática em que vive (BRASIL, 1998).

Os Parâmetros Curriculares Nacionais (datados de 1998) constituem instrumento auxiliar fundamental para se conduzir as aulas de Geografia num formato mais ou menos padronizado no âmbito do território brasileiro. Já as Diretrizes Curriculares Estaduais vigentes no estado do Paraná foram elaboradas a partir de 2005 e indicam uma abordagem dos conteúdos fundamentada em quatro eixos principais, os quais são denominados de conteúdos estruturantes. São eles: A dimensão econômica do espaço geográfico, a dimensão política do espaço geográfico, a dimensão socioambiental do espaço geográfico e a dimensão cultural e demográfica do espaço geográfico.

Os documentos atualmente vigentes fundamentam o trabalho do docente com vistas aos educandos possuírem uma formação holística, no que tange aos aspectos sociais, culturais e ambientais.

Em relação à EA atrelada a Geografia, somente a partir da década de 1990 é que os educadores começaram a trabalhar com ela em suas aulas com relativo fôlego, numa fase de transição entre a adoção da abordagem teóricometodológica fundamentada nas correntes tradicional e crítica.

Fatores como a promulgação da Constituição Federal em 1988 atrelada ao evento da $2^{\underline{a}}$ Conferência das Nações Unidas para o Meio Ambiente (Rio

\footnotetext{
7 No dia a dia da sala de aula, muitos educadores adotam uma postura tradicional diante dos conteúdos de livros didáticos, dos procedimentos metodológicos, das Diretrizes Curriculares Estaduais e Parâmetros Curriculares Nacionais de Geografia em todo o país. Moraes (2007) indica que no aspecto teórico a Geografia Tradicional está acabada, porém, ainda subsiste em mentes e instituições conservadoras.
}

Revbea, Rio Grande, V. 8, № 2:10-19, 2013. 
92), com conseqüente divulgação da Agenda 21, a publicação dos Parâmetros Curriculares Nacionais de Geografia (1998), dos Parâmetros que tratam dos temas transversais e da Lei no 9.795/99 certamente foram os pilares para a apreensão da EA pela Geografia e demais disciplinas.

Além do grande debate gerado na época dos eventos/adventos acima referidos, tais documentos constituem-se nos principais fundamentos teóricos e legais que justificam a EA no processo ensino-aprendizagem.

Cabe destacar as considerações de Bruggüer (2004) na qual a autora indica que a educação é um processo contínuo, abrangente e complexo, onde as pessoas devem possuir formação e não serem simplesmente adestradas a se comportarem diante de problemas socioambientais.

Aos docentes também devem ter consciência de que não é somente no âmbito da Geografia escolar, ou apenas com a atuação da escola que os educandos terão uma formação "ambientalmente correta". O papel dos pais e da sociedade civil organizada é fundamental no sentido de auxiliar o trabalho desenvolvido pelas instituições de ensino, contribuindo também para a formação educacional do estudante.

\section{RESULTADOS E DISCUSSÕES}

Existem inúmeras possibilidades de se trabalhar aspectos envolvendo a EA no âmbito da disciplina de Geografia, por meio de diversas técnicas de ensino. Pode-se citar como exemplos: exibição de vídeos, elaboração de cartazes e redações, análise de fotografias, entrevistas (para resgatar a história e como era o ambiente) com antigos moradores da região em que a instituição educacional está situada, trabalhos envolvendo reciclagem de materiais gerados no próprio ambiente escolar, construção de hortas e composteiras, entre outros. Todas essas atividades são apenas sugestões, onde as mesmas podem ser desenvolvidas dentro do próprio ambiente escolar.

Atividades extraclasse como estudo do meio, visitas a museus, a áreas de proteção permanente, caminhadas ecológicas no meio urbano e/ou rural e interpretação de trilhas são alguns exemplos de atividades que também podem ser realizadas com os educandos.

Além das técnicas de ensino, cabe ressaltar os conhecimentos socioambientais, políticos e culturais que a Geografia escolar possibilita aos estudantes. A forma de compreender o contexto onde os mesmos vivem é um dos grandes diferenciais ${ }^{8}$ da supracitada disciplina em relação às demais existentes nas grades curriculares das instituições de ensino.

${ }^{8}$ A intenção não é de afirmar nem sugerir que a Geografia seja mais importante que as outras disciplinas escolares, mas sim deixar explícito que a mesma possui um grande potencial em contribuir para a formação de um cidadão que possua uma visão abrangente e que compreenda aspectos envolvendo a dinâmica socioambiental do mundo em que vive. 
No que concerne aos desafios, estes envolvem uma gama variada de fatores que acabam tornando muitas vezes os trabalhos "limitados". Pode-se citar como exemplos: falta de verba e condução para os alunos realizarem trabalhos de campo, falta de materiais didático-pedagógicos específicos disponíveis nas escolas, falta de flexibilidade na troca de horários com outros docentes para a realização de atividades, falta de conhecimentos conceituais, teórico-metodológicos e práticos dos docentes para realização de atividades envolvendo a EA e falta de perspectiva interdisciplinar no processo ensinoaprendizagem envolvendo equipes pedagógicas, docentes e direção escolar no que se refere à liberação de docentes de outras disciplinas para realização de determinadas atividades práticas em conjunto, como saídas de campo, por exemplo.

Nesse sentido, é de fundamental importância a participação de professores provenientes de outros campos do conhecimento para que os educandos possam compreender assuntos relacionados à área socioambiental, pois apenas a disciplina de Geografia não pode dar conta de explicar determinados temas sem relacionar-se com outras matérias componentes da grade curricular.

A adoção de procedimentos didático-pedagógicos pautados na interdisciplinaridade pode contribuir na formação dos educandos, promovendo uma visão mais abrangente e integrada em relação à questão socioambiental em geral e ao contexto onde vivem.

Dessa forma, a interdisciplinaridade, é aqui entendida como uma prática pedagógica, onde o conhecimento é organizado no processo ensinoaprendizagem de uma forma que se possam compreender melhor os problemas socioambientais atualmente vigentes. Assim, adota-se aqui a definição apresentada por Carvalho (2006), onde esta autora comenta que a interdisciplinaridade deseja a abertura de um espaço para mediação entre determinados conhecimentos e a articulação destes, no qual as disciplinas estejam em situação de mútua coordenação e cooperação, para a compreensão da realidade.

Diversos docentes das instituições de ensino fundamental e médio negam-se em realizar atividades extraclasse envolvendo EA. Os argumentos são diversificados, variando desde a falta de tempo para planejar tais atividades, passando por problemas relacionados à condução dos alunos e falta de verba para saídas a campo e indisciplina por parte dos estudantes, por exemplo.

Um número significativo de docentes permanece ligado aos conteúdos dos livros didáticos e ao seu planejamento anual (geralmente realizado antes do início do ano letivo) não gerando espaço para a "inserção" da EA em suas práticas pedagógicas.

Além disso, existe certa resistência dentro das escolas em relação à execução de trabalhos envolvendo a EA, pois o ideal seria que a mesma fosse praticada de forma contínua e articulada ao Projeto Político Pedagógico das Revbea, Rio Grande, V. 8, № 2:10-19, 2013. 
escolas. Porém, na prática, este "trabalho ideal", contínuo e articulado não ocorre. Predominam os trabalhos pontuais, em datas importantes (dia da árvore, semana de meio ambiente, entre outras) e, majoritariamente sem concatenação com os conteúdos geográficos.

No âmbito escolar a EA, raramente, é planejada levando-se em consideração o Projeto Político-Pedagógico das instituições de ensino e os planos de aula (BARCELOS, 2008, p. 71) dos docentes da disciplina de Geografia.

A abordagem interdisciplinar, já preconizada em 1977 na Conferência de Tbilisi, na Agenda 21 publicada em 1992 e na Lei no 9.795/99, por exemplo, que deveria estar presente nos trabalhos envolvendo $E A$, quando ocorrem, ainda se apresentam de maneira incipiente e desarticulada com o contexto dos educandos.

Nesse sentido, fica evidente que, por mais que a Lei 9.795/99 trate da obrigatoriedade da EA no ensino formal, a mesma fica à disposição da boa vontade dos docentes em fazer cumprir a legislação em vigor. À equipe pedagógica e direção cabe a função de apoiar e orientar o desenvolvimento de trabalhos dos docentes de Geografia (e das outras disciplinas) no sentido de fazer cumprir a supracitada lei e seu decreto regulamentador ${ }^{9}$.

\section{CONSIDERAÇÕES FINAIS}

Apesar das inúmeras dificuldades que envolvem o trabalho de EA na Geografia escolar, existem elementos que justificam esta postura "políticopedagógica" viável e importante para a formação dos educandos.

A orientação teórico-metodológica atualmente vigente na Geografia, fundamentada na criticidade e atrelada a temas ambientais com essência geográfica, são perfeitamente aplicáveis a atual conjuntura social, ambiental, econômica e cultural no sentido de promover mudanças substanciais no comportamento dos alunos no tocante à questão socioambiental.

A EA no âmbito da Geografia, além de poder promover a sensibilização e conscientização em relação à temática ambiental, deve ser utilizada para a solução e/ou minimização de problemas $^{10}$ locais, numa perspectiva interdisciplinar devido à aplicabilidade dos conhecimentos geográficos no contexto escolar e no contexto da comunidade onde os estudantes residem.

\footnotetext{
9 O decreto $n^{\circ} 4.281$ de 2002 regulamenta a Lei $n^{\circ}$ 9.795, de 27 de abril de 1999, que institui a Política Nacional de Educação Ambiental.

10 Pode-se citar como exemplo de atividades que visem a solução e/ou minimização de problemas socioambientais em que a Geografia escolar pode contribuir: plantio de árvores nativas ao longo de cursos d'água, implantação de programas de coleta seletiva de resíduos sólidos, campanhas de economia de recursos hídricos e de energia elétrica.
} 
A EA deve contribuir para a compreensão dos processos sociais e naturais (LEFF, 2008), os quais possuem uma inter-relação e constituem a base de sustentação das pessoas que vivem sob a égide do capitalismo.

Cabe aos docentes de todas as disciplinas, às instituições escolares e também à sociedade civil estarem atentos para o cumprimento da lei alusiva a EA com o intuito de contribuir para a formação de cidadãos aptos a compreender e atuar criticamente no contexto onde vivem. Portanto, o papel dos estudantes nas escolas não pode ficar restrito apenas à meros receptores de informações socioambientais, mas sim, atuarem ativamente, conforme preconiza, inclusive a própria abordagem crítica.

\section{REFERÊNCIAS}

ARANHA, M. L. A. Filosofia da educação. São Paulo: Moderna, 1989.

BARCELOS, V. Educação Ambiental: Sobre princípios, metodologias e atitudes. Rio de Janeiro: Vozes, 2008.

BRASIL. Parâmetros Curriculares Nacionais: Geografia (terceiro e quarto ciclos). Brasília: Ministério da Educação e Cultura. 1998.

BRASIL. Lei 9.795, de 27 de abril de 1999: Dispõe sobre a educação ambiental, institui a Política Nacional de Educação Ambiental e dá outras providências. Disponível em: www.planalto.gov.br. Acesso em: 16 jul. 2010.

BRUGGÜER, P. Educação ou adestramento ambiental? 3. ed. Chapecó: Argos e Letras contemporâneas, 2004.

CALLONI, H. A educação e seus impasses: um olhar a partir da noção de pósmodernidade. In: LAMPERT, E. Pós-modernidade e conhecimento: Educação, sociedade, ambiente e comportamento humano. Porto Alegre: Sulina, 2005. p.49-75.

CARVALHO, I. C. M. Educação ambiental: a formação do sujeito ecológico. 2. ed. São Paulo: Cortez, 2006.

FREIRE, P. Pedagogia do oprimido. 30. ed. São Paulo: Paz e Terra, 1987.

DIAS, G.F. Educação ambiental: princípios e práticas. 5. ed. São Paulo: Global, 1998.

LAMPERT, E. Pós-modernidade e educação. In: LAMPERT, E. Pósmodernidade e conhecimento: educação, sociedade, ambiente e comportamento humano. Porto Alegre: Sulina, 2005. p. 11-48.

LEFF, H. Saber ambiental: sustentabilidade, racionalidade, complexidade e poder. 6. ed. Petrópolis: Vozes, 2008.

LIBÂNEO, J.C.; OLIVEIRA, J.F.; TOSCHI, M.S. Educação escolar: políticas, estrutura e organização. 5. ed. São Paulo: Cortez, 2007. 
MANUCCI, M. Sociedade sustentável. In: HAMMES, V.S. Proposta metodológica de macroeducação. 2. ed. São Paulo: 2004, p. 25-28.

MORAES, A.C.R. Geografia: pequena história crítica. 21. ed. São Paulo: Hucitec, 2007.

MORIN, E. Complexidade e ética da solidariedade. In: CASTRO, G.; CARVALHO, E. A.; ALMEIDA, M. C. Ensaios de Complexidade. Sulina: Porto Alegre, 1997, p. 15-24.

PARANÁ. Diretrizes Curriculares: Geografia. Curitiba: Secretaria de Estado da Educação. 2008.

PENNA, C.G. O estado do Planeta: Sociedade de consumo e degradação ambiental. Rio de Janeiro: Record, 1999.

PONTUSCHKA, N.N.; PAGANELLI, T.I.; CACETE, N.H. Para ensinar e aprender Geografia. São Paulo: Cortez, 2007.

SOFFIATI, A. Fundamentos filosóficos e históricos para o exercício da ecocidadania e da ecoeducação. In: BIANCHINI BAETA, A.M. et al. Educação Ambiental: repensando o espaço da cidadania. 3. ed. São Paulo: Cortez, 2005. p. 23-68.

TOZZONI-REIS, M.F.C. Educação Ambiental: natureza, razão e história. 2. ed. Campinas: Autores associados, 2008. 